\title{
Manifiesto Liminar
}

Introdução, transcrição e tradução para o português de Adrián Pablo Fanjul, coorganizador deste número e professor do Programa de Pós-Graduação em Língua Espanhola e Literaturas Espanhola e Hispano-Americana da Faculdade de Filosofia, Letras e Ciências Humanas da Universidade de São Paulo. A transcrição foi feita conforme a versão publicada no portal que a Universidad Nacional de Córdoba estabeleceu para as comemorações do Centenário da Reforma, https:// centenariodelareforma.unc.edu.ar/ corrigindo apenas o que pareceu ser erro de digitação. 


\section{LA GACETA UNIVERSITARIA

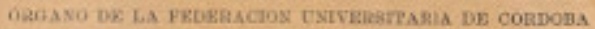

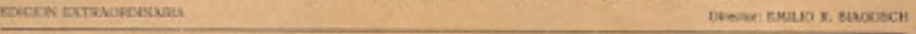

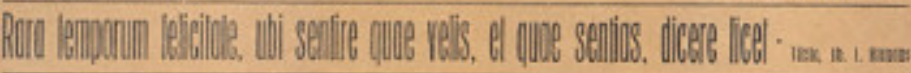

\section{La juventud argentina de Córdoba}

A los hombres libres de Sud América MANIFIESTO DE LA F. U. DE CÓRDOBA

Esta declaração, que transcendeu historicamente como "Manifiesto Liminar", foi publicada em La Gaceta Universitaria, periódico da Federación Universitária de Córdoba, entidade representativa estudantil que protagonizou organicamente a revolta conhecida como Reforma de 1918. A data é de 21 de junho daquele ano. Foi assinada por um grupo de estudantes detalhado no final, dentre os quais não consta aquele que é considerado seu principal autor, Deodoro Roca. O artigo de Eduardo Rinesi que publicamos neste número, "Dieciocho apuntes sobre el Dieciocho", desenvolve análises deste texto. Apresentamos aqui também uma tradução para o português. 


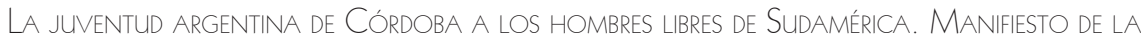
Federación UINIVERSITARIA de Córdoba

Hombres de una república libre, acabamos de romper la última cadena que en pleno siglo XX nos ataba a la antigua dominación monárquica y monástica. Hemos resuelto llamar a todas las cosas por el nombre que tienen. Córdoba se redime. Desde hoy contamos para el país una vergüenza menos y una libertad más. Los dolores que nos quedan son las libertades que nos faltan. Creemos no equivocarnos, las resonancias del corazón nos lo advierten: estamos pisando sobre una revolución, estamos viviendo una hora americana.

La rebeldía estalla ahora en Córdoba y es violenta, porque aquí los tiranos se habían ensoberbecido y porque era necesario borrar para siempre el recuerdo de los contrarrevolucionarios de Mayo. Las universidades han sido hasta aquí el refugio secular de los mediocres, la renta de los ignorantes, la hospitalización segura de los inválidos y - lo que es peor aún - el lugar en donde todas las formas de tiranizar y de insensibilizar hallaron la cátedra que las dictara. Las universidades han llegado a ser así el fiel reflejo de estas sociedades decadentes que se empeñan en ofrecer el triste espectáculo de una inmovilidad senil. Por eso es que la Ciencia, frente a estas casas mudas y cerradas, pasa silenciosa o entra mutilada y grotesca al servicio burocrático. Cuando en un rapto fugaz abre sus puertas a los altos espíritus es para arrepentirse luego y hacerles imposible la vida en su recinto. Por eso es que, dentro de semejante régimen, las fuerzas naturales llevan a mediocrizar la enseñanza, y el ensanchamiento vital de los organismos universitarios 
no es el fruto del desarrollo orgánico, sino el aliento de la periodicidad revolucionaria.

Nuestro régimen universitario - aún el más reciente - es anacrónico. Está fundado sobre una especie del derecho divino: el derecho divino del profesorado universitario. Se crea a sí mismo. En él nace y en él muere. Mantiene un alejamiento olímpico. La Federación Universitaria de Córdoba se alza para luchar contra este régimen y entiende que en ello le va la vida. Reclama un gobierno estrictamente democrático y sostiene que el demos universitario, la soberanía, el derecho a darse el gobierno propio radica principalmente en los estudiantes. El concepto de Autoridad que corresponde y acompańa a un director o a un maestro en un hogar de estudiantes universitarios no sólo puede apoyarse en la fuerza de disciplinas extrañas a la substancia misma de los estudios. La autoridad en un hogar de estudiantes no se ejercita mandando, sino sugiriendo y amando: enseñando. Si no existe una vinculación espiritual entre el que enseña y el que aprende, toda enseñanza es hostil y de consiguiente infecunda. Toda la educación es una larga obra de amor a los que aprenden. Fundar la garantía de una paz fecunda en el artículo conminatorio de un reglamento o de un estatuto es, en todo caso, amparar un régimen cuartelario, pero no una labor de Ciencia. Mantener la actual relación de gobernantes a gobernados es agitar el fermento de futuros trastornos. Las almas de los jóvenes deben ser movidas por fuerzas espirituales. Los gastados resortes de la autoridad que emana de la fuerza no se avienen con lo que reclama el sentimiento y el concepto moderno de las universidades. El chasquido del látigo sólo puede rubricar el silencio de los inconscientes o de los cobardes. La única actitud silenciosa, 
que cabe en un instituto de Ciencia es la del que escucha una verdad o la del que experimenta para crearla o comprobarla. Por eso queremos arrancar de raíz en el organismo universitario el arcaico y bárbaro concepto de Autoridad que en estas Casas es un baluarte de absurda tiranía y sólo sirve para proteger criminalmente la falsa-dignidad y la falsa-competencia.

Ahora advertimos que la reciente reforma, sinceramente liberal, aportada a la Universidad de Córdoba por el Dr. José Nicolás Matienzo, sólo ha venido a probar que el mal era más afligente de lo que imaginábamos y que los antiguos privilegios disimulaban un estado de avanzada descomposición. La reforma Matienzo no ha inaugurado una democracia universitaria; ha sancionado el predominio de una casta de profesores. Los intereses creados en torno de los mediocres han encontrado en ella un inesperado apoyo. Se nos acusa ahora de insurrectos en nombre de un orden que no discutimos, pero que nada tiene que hacer con nosotros. Si ello es así, si en nombre del orden se nos quiere seguir burlando y embruteciendo, proclamamos bien alto el derecho sagrado a la insurrección. Entonces la única puerta que nos queda abierta a la esperanza es el destino heroico de la juventud. El sacrificio es nuestro mejor estímulo; la redención espiritual de las juventudes americanas nuestra única recompensa, pues sabemos que nuestras verdades lo son - y dolorosas - de todo el continente. Que en nuestro país una ley se dice - la de Avellaneda, se opone a nuestros anhelos. Pues a reformar la ley, que nuestra salud moral lo está exigiendo.

La juventud vive siempre en trance de heroísmo. Es desinteresada, es pura. No ha tenido tiempo aún de contaminarse. No se equivoca nunca en la elección de sus propios maestros. Ante los jóvenes no se hace mérito 
adulando o comprando. Hay que dejar que ellos mismos elijan sus maestros $\mathrm{y}$ directores, seguros de que el acierto ha de coronar sus determinaciones. En adelante sólo podrán ser maestros en la futura república universitaria los verdaderos constructores de alma, los creadores de verdad, de belleza y de bien. La juventud universitaria de Córdoba cree que ha llegado la hora de plantear este grave problema a la consideración del país y de sus hombres representativos.

Los sucesos acaecidos recientemente en la Universidad de Córdoba, con motivo de elección rectoral, aclaran singularmente nuestra razón en la manera de apreciar el conflicto universitario. La Federación Universitaria de Córdoba cree que debe hacer conocer al país y a América las circunstancias de orden moral y jurídico que invalidan el acto electoral verificado el 15 de junio. Al confesar los ideales y principios que mueven a la juventud en esta hora única de su vida, quiere referir los aspectos locales del conflicto y levantar bien alta la llama que está quemando el viejo reducto de la opresión clerical. En la Universidad Nacional de Córdoba y en esta ciudad no se han presenciado desórdenes; se ha contemplado y se contempla el nacimiento de una verdadera revolución que ha de agrupar bien pronto bajo su bandera a todos los hombres libres del continente. Referiremos los sucesos para que se vea cuánta vergüenza nos sacó a la cara la cobardía y la perfidia de los reaccionarios. Los actos de violencia, de los cuales nos responsabilizamos íntegramente, se cumplían como en el ejercicio de puras ideas. Volteamos lo que representaba un alzamiento anacrónico y lo hicimos para poder levantar siquiera el corazón sobre esas ruinas. Aquellos representan también la medida de nuestra indignación en presencia de la miseria moral, de la 
simulación y del engaño artero que pretendía filtrarse con las apariencias de la legalidad. El sentido moral estaba oscurecido en las clases dirigentes por un fariseísmo tradicional y por una pavorosa indigencia de ideales.

El espectáculo que ofrecía la Asamblea Universitaria era repugnante. Grupos de amorales deseosos de captarse la buena voluntad del futuro rector exploraban los contornos en el primer escrutinio, para inclinarse luego al bando que parecía asegurar el triunfo, sin recordar la adhesión públicamente empeñada en el compromiso de honor contraído por los intereses de la Universidad. Otros - los más - en nombre del sentimiento religioso y bajo la advocación de la Compañía de Jesús, exhortaban a la traición y al pronunciamiento subalterno. (¡Curiosa religión que enseńa a

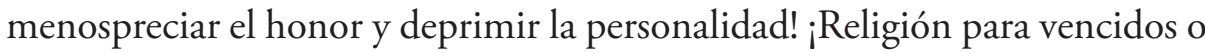
para esclavos!). Se había obtenido una reforma liberal mediante el sacrificio heroico de una juventud. Se creía haber conquistado una garantía y de la garantía se apoderaban los únicos enemigos de la reforma. En la sombra los jesuitas habían preparado el triunfo de una profunda inmoralidad. Consentirla habría comportado otra traición. A la burla respondimos con la revolución. La mayoría expresaba la suma de represión, de la ignorancia y del vicio. Entonces dimos la única lección que cumplía y espantamos para siempre la amenaza del dominio clerical.

La sanción moral es nuestra. El derecho también. Aquellos pudieron obtener la sanción jurídica, empotrarse en la Ley. No se lo permitimos. Antes de que la iniquidad fuera un acto jurídico, irrevocable y completo, nos apoderamos del Salón de Actos y arrojamos a la canalla, solo entonces amedrentada, a la vera de los claustros. Que es cierto, lo patentiza el hecho de haber, a continuación, 
sesionado en el propio Salón de Actos la Federación Universitaria y de haber firmado mil estudiantes, sobre el mismo pupitre rectoral, la declaración de la huelga indefinida. En efecto, los estatutos reformados disponen que la elección de rector terminará en una sola sesión, proclamándose inmediatamente el resultado, previa lectura de cada una de las boletas y aprobación del acta respectiva. Afirmamos, sin temor de ser rectificados, que las boletas no fueron leídas, que el acta no fue aprobada, que el rector no fue proclamado, y que, por consiguiente, para la ley, aún no existe rector de esta universidad.

La juventud universitaria de Córdoba afirma que jamás hizo cuestión de nombres ni de empleos. Se levantó contra un régimen administrativo, contra un método docente, contra un concepto de autoridad. Las funciones públicas se ejercitaban en beneficio de determinadas camarillas. No se reformaban ni planes ni reglamentos por temor de que alguien en los cambios pudiera perder su empleo. La consigna de "hoy para ti, mañana para mí", corría de boca en boca y asumía la preeminencia de estatuto universitario. Los métodos docentes estaban viciados de un estrecho dogmatismo, contribuyendo a mantenera la Universidad apartada de la Ciencia y de las disciplinas modernas. Las lecciones, encerradas en la repetición interminable de viejos textos, amparaban el espíritu de rutina y de sumisión. Los cuerpos universitarios, celosos guardianes de los dogmas, trataban de mantener en clausura a la juventud, creyendo que la conspiración del silencio puede ser ejercitada en contra de la Ciencia. Fue entonces cuando la oscura Universidad Mediterránea cerró sus puertas a Ferri, a Ferrero, a Palacios y a otros, ante el temor de que fuera perturbada su plácida ignorancia. Hicimos entonces una santa revolución y el régimen cayó a nuestros golpes. 
Creímos honradamente que nuestro esfuerzo había creado algo nuevo, que por lo menos la elevación de nuestros ideales merecía algún respeto. Asombrados, contemplamos entonces cómo se coaligaban para arrebatar nuestra conquista los más crudos reaccionarios. No podemos dejar librada nuestra suerte a la tiranía de una secta religiosa, no al juego de intereses egoístas. A ellos se nos quiere sacrificar. El que se titula rector de la Universidad de San Carlos ha dicho su primera palabra: "prefiero antes de renunciar que quede el tendal de cadáveres de los estudiantes". Palabras llenas de piedad y amor, de respeto reverencioso a la disciplina; palabras dignas del jefe de una casa de altos estudios. No invoca ideales ni propósitos de acción cultural. Se siente custodiado por la fuerza y se alza soberbio y amenazador. ¡Armoniosa lección que acaba de dar a la juventud el primer ciudadano de una democracia universitaria! Recojamos la lección, compañero de toda América; acaso tenga el sentido de un presagio glorioso, la virtud de un llamamiento a la lucha suprema por la libertad; ella nos muestra el verdadero carácter de la autoridad universitaria, tiránica y obcecada, que ve en cada petición un agravio y en cada pensamiento una semilla de rebelión.

La juventud ya no pide. Exige que se le reconozca el derecho a exteriorizar ese pensamiento propio de los cuerpos universitarios por medio de sus representantes. Está cansada de soportar a los tiranos. Si ha sido capaz de realizar una revolución en las conciencias, no puede desconocérsele la capacidad de intervenir en el gobierno de su propia casa. 
La juventud universitaria de Córdoba, por intermedio de su Federación, saluda a los compañeros de la América toda y les incita a colaborar en la obra de libertad que inicia.

21 de junho de 1918 Enrique F. Barros, Horacio Valdés, Ismael C. Bordabehere, presidente. Gurmensindo Sayago, Alfredo Castellanos, Luis M. Méndez, Jorge L. Bazante, Ceferino Garzón Maceda, Julio Molina, Carlos Suárez Pinto, Emilio R. Biagosch, Angel J. Nigro, Natalio J. Saibene, Antonio Medina Allende, Ernesto Garzón.

\section{A juventude argentina de Córdoba aos homens livres da América do Sul. Manifesto da} Federação Universitária de Córdoba

Homens de uma república livre, acabamos de quebrar a última corrente que, em pleno século XX, amarrava-nos à antiga dominação monárquica e monástica. Resolvemos chamar todas as coisas pelo nome que elas têm. Córdoba se redime. A partir de hoje, damos ao país uma vergonha a menos e uma liberdade a mais. As dores que ainda permanecem são as liberdades que nos faltam. Cremos não estar equivocados, as ressonâncias do coração nos advertem: estamos pisando em uma revolução, estamos vivendo uma hora americana. 
A rebeldia explode agora em Córdoba e é violenta, porque aqui os tiranos tinham-se ensoberbado e porque era necessário apagar para sempre a lembrança dos contrarrevolucionários de Maio. As universidades foram até agora o refúgio secular dos medíocres, a renda dos ignorantes, a hospitalização certa dos inválidos e, o que é ainda pior, o local onde todas as formas de tiranizar e de insensibilizar encontraram a cátedra que as ministrasse. Desse modo, as universidades chegaram a ser o reflexo dessas sociedades decadentes que teimam em oferecer o triste espetáculo de uma imobilidade senil. É por isso que a Ciência, diante dessas casas mudas e fechadas, passa silenciosa ou entra mutilada e grotesca para um serviço burocrático. Quando fugazmente a casa abre suas portas aos altos espíritos, é para se arrepender logo e infernizar a vida deles. Por isso, dentro desse regime, as forças naturais conduzem o ensino para a mediocridade, e o alargamento vital dos órgãos universitários não é fruto do desenvolvimento orgânico, mas do estímulo da periodicidade revolucionária.

Nosso regime universitário - inclusive o mais recente - é anacrônico. É embasado em uma espécie do direito divino: o direito divino do professorado universitário. Ele cria a si mesmo. Em si nasce e em si morre. Ele mantém um afastamento olímpico. A Federação Universitária de Córdoba se levanta para lutar contra este regime e entende que, nessa luta, entra em jogo sua própria existência. Demanda um governo estritamente democrático e defende que o demos universitário, a soberania, o direito a eleger o próprio governo radica principalmente nos estudantes. $\mathrm{O}$ conceito de Autoridade que corresponde e acompanha um diretor ou um professor em um lar de estudantes universitários não pode apoiar-se apenas na força 
de disciplinamentos alheios à substância mesma dos estudos. A autoridade em um lar de estudantes não se exerce mandando, mas sugerindo e amando: ensinando. Se náo existe um vínculo espiritual entre quem ensina e quem aprende, todo ensinoé hostil, e, em consequência, infecundo. A educação toda é uma longa obra de amor por aqueles que aprendem. Fundar a garantia de uma paz fecunda no artigo cominatório de um regulamento ou de um estatuto é, em todo caso, amparar um regime de quartel, mas não fazer Ciência. Manter a atual relação entre governantes e governados é semear futuros transtornos. As almas dos jovens devem ser movidas por forças espirituais. As molas desgastadas da autoridade que emana da força náo se dáo bem com o que reclamam o sentimento e o conceito moderno das universidades. $\mathrm{O}$ estrondo do chicote só pode afirmar o silêncio dos inconscientes ou dos covardes. A única atitude silenciosa que cabe em um instituto de Ciência é a de quem escuta uma verdade ou a de quem experimenta para criá-la ou comprová-la. Por isso, queremos desarraigar do organismo universitário o arcaico e bárbaro conceito de Autoridade que nestas Casas é marco de absurda tirania e somente serve para proteger criminalmente a falsa-dignidadee a falsa-competência.

Agora percebemos que a recente reforma, sinceramente liberal, trazida à Universidade de Córdoba pelo Dr. José Nicolás Matienzo, só veio provar que o mal era mais preocupante do que imaginávamos e que os antigos privilégios dissimulavam um estado de avançada decomposição. A reforma Matienzo não inaugurou uma democracia universitária; ela chancelou o predomínio de uma casta de professores. Os interesses criados em torno dos medíocres encontraram nela um inesperado apoio. Agora somos acusados 
de insurrectos em nome de uma ordem que nós não discutimos, mas que em nada nos diz respeito. Se isso é assim, se em nome da ordem pretendese dar continuidade à burla e ao nosso embrutecimento, proclamamos bem alto o direito sagrado à insurreição. Portanto, o destino heroico da juventude é a única porta que fica aberta para a esperança. O sacrifício é nosso melhor estímulo; a redenção espiritual das juventudes americanas é nossa única recompensa, pois sabemos que as nossas verdades doem, e que são do continente todo. Sabemos também que, no nosso país, uma lei (dizem que de Avellaneda) é obstáculo para as nossas aspiraçôes. Cabe, então, reformar a lei, porque nossa saúde moral o exige.

A juventude vive sempre em transe de heroísmo. Ela é desinteressada, pura. Ainda não teve tempo de contaminar-se. Nunca erra na escolha dos seus próprios mestres. Perante os jovens ninguém faz mérito lisonjeando ou comprando. É necessário deixar que eles mesmos escolham seus mestres e diretores, com a certeza de que o sucesso há de coroar suas determinaçóes. Daqui para a frente, somente poderão ser mestres na futura república universitária os verdadeiros construtores de alma, os criadores de verdade, de beleza e de bem. A juventude universitária de Córdoba acredita que chegou a hora de expor este grave problema para a consideração do país e de seus homens representativos.

Os recentes acontecimentos na Universidade de Córdoba, com motivo da eleição reitoral, esclarecem singularmente nossa razão no modo como avaliamos o conflito universitário. A Federação Universitária de Córdoba considera necessário fazer com que o país e a América conheçam as circunstâncias de ordem moral e jurídica que invalidam a eleição realizada 
no dia 15 de junho. Ao declarar os ideais e princípios que mobilizam a juventude nesta hora única da sua vida, ela quer referir os aspectos locais do conflito e levantar bem alta achama que está queimando o velho reduto da opressão clerical. Na Universidade Nacional de Córdoba e nesta cidade não foram vistas arruaças; foi visto e se vê o nascimento de uma verdadeira revolução, que logo reunirá sob sua bandeira todos os homens livres do continente. Referiremos os acontecimentos para que se perceba quanta vergonha foi escancarada pela covardia e a perfídia dos reacionários. Os atos de violência, sobre os quais assumimos total responsabilidade, cumpriramse como exercício de puras ideias. Derrubamos o que representava um levante anacrônico e fizemos isso para poder alçar pelo menos o coração por cima dessas ruínas. Aqueles atos representam também a medida da nossa indignaçãona presença da miséria moral, da simulação e do engano ardiloso que pretendia esconder-se nas aparências de legalidade. $\mathrm{O}$ sentido moral estava obscurecido nas classes dirigentes por um farisaísmo tradicional e por uma pavorosa indigência de ideais.

O espetáculo que oferecia a Assembleia Universitária era repugnante. Grupos de imorais ávidos por angariar para si a boa vontade do futuro reitor circulavam pelos contornos durante a primeira apuração para, depois, decidirem pelo lado que parecia garantir a vitória, esquecendo da adesão publicamente manifestada no compromisso de honra contraído em prol dos interesses da Universidade. Outros (mais numerosos) em nome do sentimento religioso e invocando a Companhia de Jesus, exortavam à traição e ao pronunciamento subalterno. (Estranha religião que ensina a menosprezar a honra e a deprimir a personalidade! Religião para vencidos ou 
para escravos!). Uma reforma liberal tinha sido obtida com base no sacrifício heroico de uma juventude. Acreditava-se ter conquistado uma garantia, mas essa garantia era apropriada pelos únicos inimigos da reforma. Das sombras, os jesuítas tinham preparado a vitória de uma profunda imoralidade. Consentir teria significado uma nova traição. A burla foi contestada com a revolução. A maioria expressava a soma de repressão, ignorância e vício. Então, demos a única lição que cabia e afugentamos para sempre a ameaça do domínio clerical.

Asanção moral é nossa. O direito também. Os outros puderam obter a sanção jurídica, resguardar-sem a Lei. E nós não permitimos. Antes que a iniquidade fosse um ato jurídico, irrevogável e completo, ocupamos o Salão de Atos e enxotamos a corja, só nesse momento amedrontada, para o lado de fora dos claustros. Essa verdade é atestada pelo fato de, logo em seguida, a Federação Universitária ter-se reunido no mesmo Salão, e de que mil estudantes assinaram, na própria mesa reitoral, a deflagração da greve geral por tempo indeterminado. Com efeito, os estatutos reformados dispóem que a eleição de reitor se esgota numa única sessão, sendo proclamado imediatamente o resultado, prévia leitura de cada uma das cédulas e aprovação da respectiva ata. Afirmamos, sem temor de sermos retificados, que as cédulas não foram lidas, que a ata não foi aprovada, que o reitor não foi proclamado, e que, portanto, para a lei, não existe ainda reitor desta universidade.

A juventude universitária de Córdoba afirma que jamais fez questão de nomes nem de empregos. Alçou-se contra um regime administrativo, contra um método docente, contra um conceito de autoridade. As funções 
públicas eram exercidas em benefício de determinados grupos. Planos de estudo e regulamentos não eram reformados por temor de que alguém perdesse seu emprego com as mudanças. O lema "hoje para você, amanhã para mim" corria de boca em boca e assumia a preeminência de estatuto universitário. Os métodos docentes estavam viciados por um estreito dogmatismo, contribuindo para manter a Universidade afastada da Ciência e das disciplinas modernas. As liçóes, fechadas na repetiçáo interminável de velhos textos, amparavamo espírito de rotina e de submissão. Os corpos universitários, zelosos guardióes dos dogmas, tentavam manter a juventude em clausura, acreditando que a conspiraçáo do silêncio pode ser exercida contra a Ciência. Foi então quando a obscura Universidade Mediterrânea fechou suas portas a Ferri, a Ferrero, a Palaciose a outros, com temor de que sua plácida ignorância fosse perturbada. Fizemos, entâo, uma santa revolução e o regime caiu pelos nossos golpes.

Acreditamos honradamente que o nosso esforço tinha criado algo novo, que pelo menos a elevação dos nossos ideais merecia algum respeito. Espantados, contemplamos entáo como os mais toscos reacionários se coligavam para nos arrancar nossa conquista. Náo podemos confiar nossa sorte à tirania de uma seita religiosa nem ao jogo de interesses egoístas. É a eles que se pretende que nos sacrifiquemos. Aquele que se titula reitor da Universidade de San Carlos já disse sua primeira palavra: "antes que renunciar, prefiro que fique um mar de cadáveres de estudantes". Palavras plenas de piedade e amor, de respeito reverencioso pela disciplina; palavras dignas do chefe de uma casa de altos estudos. Não invoca ideais nem propósitos de açáo cultural. Sente-se custodiado pela força e se levanta soberbo e ameaçador. Harmoniosa a lição 
que o primeiro cidadão de uma democracia universitária acaba de oferecer à juventude! Colhamos essa lição, companheiros da América toda; talvez ela tenha o sentido de um presságio glorioso, a virtude de uma convocatória para a luta suprema pela liberdade. Ela nos mostra o verdadeiro caráter da autoridade universitária, tirânica e obcecada, que vê em cada solicitação um acinteem cada pensamento una semente de rebelião.

A juventude já não pede. Exige que lhe seja reconhecido seu direito a exteriorizar esse pensamento próprio dos corpos universitários por meio de seus representantes. Cansou de suportar os tiranos. Se ela foi capaz de realizar uma revolução nas consciências, não há como desconhecer sua capacidade para intervir no governo da sua própria casa.

A juventude universitária de Córdoba, por meio da sua Federação, cumprimenta os companheiros da América toda,e os incita à colaboração com a obra de liberdade que ela inicia.

21 de junho de 1918 Enrique F. Barros, Horacio Valdés, Ismael C. Bordabehere, presidente. Gurmensindo Sayago, Alfredo Castellanos, Luis M. Méndez, Jorge L. Bazante, Ceferino Garzón Maceda, Julio Molina, Carlos Suárez Pinto, Emilio R. Biagosch, Angel J. Nigro, Natalio J. Saibene, Antonio Medina Allende, Ernesto Garzón. 